\title{
Lugares de Silvio Romero na Sociologia Brasileira
}

Ivan Fontes Barbosa*

Resumo

Este artigo resultou de uma pesquisa que teve a intenção de identificar algumas das imagens de Silvio Romero em trabalhos dedicados à história da sociologia brasileira e de demonstrar como os seus interesses sobre o estudo da literatura forneceram elementos para entendermos os horizontes da recepção da sociologia no Brasil nas últimas décadas do século XIX. Os resultados indicaram que as principais intuições de sua abordagem sociológica, especialmente o seu diagnóstico dos efeitos e do papel da miscigenação na sociedade brasileira, geraram uma vereda no campo da sociologia brasileira, que orientou, e ainda orienta, um paradoxal e controverso discurso sobre a nossa formação social.

Palavras-chave: Silvio Romero; Crítica literária; Sociologia no Brasil; Miscigenação.

* Professor Adjunto do Departamento de Ciências Sociais da UFPB.

Email: ivanfontesbarbosa@gmail.com 


\section{Places of Silvio Romero in Brazilian Sociology}

\section{Abstract}

This article was the result of a research that aimed to identify some of the images of Silvio Romero in works dedicated to the history of Brazilian sociology and to demonstrate how his interests on the study of literature provided elements to understand the horizons of the reception of sociology in Brazil in the last decades of the 19th century. The results indicated that the main intuitions of his sociological approach, especially his diagnosis of the effects and the role of miscegenation in Brazilian society, generated a path in the field of Brazilian sociology, which guided and still guides a paradoxical and controversial discourse on our social formation.

Keywords: Silvio Romero; Literary criticism; Sociology in Brazil; Miscegenation.

\section{Lugares de Silvio Romero en la Sociología Brasileña}

\section{Resumen}

Este artículo resultó de una investigación que tuvo la intención de identificar algunas de las imágenes de Silvio Romero en trabajos dedicados a la historia de la sociología brasileña y de demostrar cómo sus intereses sobre el estudio de la literatura proporcionaron elementos para entender los horizontes de la recepción de la sociología en Brasil en las últimas décadas del siglo XIX. Los resultados indicaron que las principales intuiciones de su abordaje sociológico, especialmente su diagnóstico de los efectos y del papel del mestizaje en la sociedad brasileña, generaron una vereda en el campo de la sociología brasileña, que 
orientó, y aún orienta, un paradojal y controvertido discurso sobre nuestra formación social.

Palabras clave: Silvio Romero; Crítica literaria; Sociología en Brasil; Miscigenación .

\section{Imagens de Silvio Romero na história da Sociologia no Brasil}

As pesquisas e escritos de Silvio Romero publicados no último quartel do século XIX ilustram a índole da sociologia brasileira daquele momento. Eles protagonizaram a construção de um controverso tipo de reflexão que foi orquestrado a partir da aplicação de modelos teóricos coloniais conjugados a pesquisas de caráter empírico. No dizer de Antônio Candido, "se já houve projeto ambicioso no Brasil, poucos terão sido mais que o desse estudante sergipano, embriagado pela divulgação da ciência europeia" (Candido,1988, p. 42).

Silvio Romero obteve destaque no cenário intelectual brasileiro por possuir um conjunto reconhecido de publicações que flertou com a Sociologia, Antropologia, Literatura, Filosofia e Direito e estava orientado para a compreensão do Brasil no contexto dos últimos decênios do século XIX. Em se tratando das suas contribuições às Ciências Sociais, orbita em torno do seu trabalho a valorização da dimensão pioneira na iniciação da investigação sociológica brasileira e na criação de uma teoria sobre o Brasil, assim como gravita um sintomático descrédito que pode ser traduzido na percepção de sua obra como uma construção exclusivamente racista e depreciada do Brasil.

Silvio Vasconcelos da Silveira Ramos Romero nasceu em Lagarto, município de Sergipe, em 1851, e faleceu no Rio de Janeiro, em 1914. Em 1868, ingressou na Faculdade de Direito do Recife (FDR), concluindo o curso de bacharel em Direito, em 1873. Iniciou sua atividade intelectual como jornalista e crítico literário no 
primeiro ano do curso, momento em que professou advogar abertamente a adesão ao positivismo de Augusto Comte e a alguns elementos da perspectiva evolucionista de Herbert Spencer.

Seus primeiros objetivos intelectuais, ligados a forte preponderância da literatura enquanto objeto e espaço de anunciação das postulações sociológicas, foram demarcar critérios para a elaboração de uma crítica literária objetiva. Mapeou e fixou as fontes e os indícios culturais que permitiram a percepção e delimitação da literatura e sua contribuição para a invenção da nação brasileira.

0 registro acerca da contribuição de Silvio Romero à nascente novecentista sociologia brasileira nos é dado por vários autores e, inclusive, por ele mesmo. Em 1885, nos "Ensaios de Filosofia e Direito" ele apontou que "quanto aos processos de observação e a transformação por eles operada em sociologia, achamo-nos de acordos e proclamamos entre nós desde 1870. Fomos talvez os primeiros a fazê-los e aproveitamos a ocasião para consigná-los de uma vez" (Romero, 2001, pp. 38-39).

Antônio Candido (1969) insinuou que:

Talvez a primeira manifestação do que seria a sociologia no Brasil durante quase meio século se encontre na Introdução à História da Literatura Brasileira (1881), onde Silvio Romero estabelece as diretrizes que orientaram por muito tempo os estudos sociais no Brasil, ao interpretar o sentido da evolução cultural e institucional segundo os fatores naturais do meio e da raça (Candido, 1969, p. 01).

As informações de Oracy Nogueira também indicaram a presença representativa de Silvio Romero na história da Sociologia Brasileira na transição do século XIX para o século XX.

No que respeita especificamente à sociologia, a figura mais eminente desta fase é a de Silvio Romero, que pode ser considerado como o primeiro estudioso da disciplina no Brasil que não se limitou a reflexões teóricas e a aplicação de qua- 
dros de referência sociológicos a interpretação da realidade nacional, empenhando-se na coleta e análise das informações sobre aspectos da sociedade e cultura nacionais, contribuindo para o seu conhecimento [...] neste sentido Silvio Romero foi atípico em relação à fase de análise e precursor de uma tendência que só mais tarde se formaria na história da sociologia no Brasil (Nogueira, 1978, p. 201).

Vamireh Chacon (1977, p. 13) declarou que o debate ocorrido na Escola do Recife (ER) no fim da década de 1870, envolvendo Silvio Romero e Tobias Barreto, sobre a possibilidade de existência de uma sociologia, representa a chegada desta ciência no Brasil. Em outra ocasião, assinalou que "Silvio Romero é um dos precursores no Brasil” (Chacon, 2008, p. 64).

Segundo Carneiro Leão (1953, p. 23), foi a partir da obra de Augusto Comte que a sociologia fez sua aparição no Brasil. Os seus primeiros centros de estudos foram as faculdades de Direito de Recife e de São Paulo. "Silvio Romero, da Escola do Recife, foi o primeiro adotar os métodos de pesquisa sociológicos de Le Play" (Leão, 1953, p. 28).

O trabalho do professor Heraldo Souto Maior (2003, p. 08) apontou que a trajetória da sociologia em Pernambuco tem início com as primeiras reflexões marcadas com um forte conteúdo de Filosofia Social, de Ciência Jurídica e, mesmo, de Literatura. O positivismo "comteano" e o evolucionismo "spenceriano" já circulavam entre nós.

É bom salientar que essas ideias e esse espírito ultrapassaram o âmbito de Recife e tiveram repercussão nacional, inclusive pela migração de vultos como Silvio Romero, Teixeira de Freitas e Bevilácqua, entre outros. Neste sentido, poderíamos dizer que a ER estava à frente ou emparelhada com outros centros brasileiros de estudo; as Faculdades de Direito eram o carro chefe que os conduziam, correspondendo à realidade social e econômica da época (Souto Maior, 2003, p. 11). 
Consoante Pinto Ferreira, não foi exagero atribuir-lhe o "honroso título de fundador da sociologia brasileira" (Ferreira, 1969, p. 262). Guerreiro Ramos atestou que:

[...] apesar de suas deficiências, homens como Visconde de Uruguai, Silvio Romero, Euclides da Cunha, Alberto Torres e Oliveira Viana em suas respectivas épocas [...] são momentos ilustres da formação de um pensamento sociológico brasileiro, que utilizavam, como subsídios, as contribuições estrangeiras (Ramos, 1996, p. 25).

Na recente abordagem de Alberto Schneider, Silvio Romero foi tido e entendido como o "sociólogo da cultura brasileira e o grande hermeneuta do Brasil” (Schneider, 2005, p. 21). Sua sugestão pode ser traduzida pela ideia de que Silvio Romero construiu uma autêntica teoria para pensar a sociedade brasileira: um modo de perceber e entender não somente a literatura brasileira, mas o país. Seguindo as instruções desse autor, podemos falar de uma tradição interpretativa de inspiração nacionalista que está assentada na ideia de mestiçagem como fator dinâmico e imprescindível no entendimento da cultura brasileira. Essa tradição tem como principais continuadores Darcy Ribeiro, Câmara Cascudo, Mario de Andrade e Gilberto Freyre (Schneider, 2005, p. 25).

Se no panorama até aqui esboçado Silvio Romero é visto como pioneiro na introdução da sociologia brasileira, os limites e os usos discursivos e ideológicos desta ciência naquele contexto também incidem sobre a avaliação de sua obra e é proporcional ao destaque que outrora ele mereceu. 0 pioneiro dessas críticas foi o seu conterrâneo e contemporâneo Manoel Bomfim [1905] (1993). Cognominando os intelectuais que partiam dos pressupostos raciais de teoristas da exploração, sociólogos do egoísmo, filósofos do massacre, e a sua sociologia de sociologia da cobiça, advertiu que a América Latina não estava condenada pelas leis gerais do progresso a viver como um povo primitivo distante da 
civilização. 0 que condenava era a dominação racista que pregava a desigualdade das nações e o neocolonialismo que impedia a independência econômica do país.

Com o avanço nos campos da sociologia do conhecimento e da história das ideias, novos olhares, marcados pela identificação das dimensões ideológicas e discursivas das Ciências Sociais, incidiram sobre os estudos dedicados à história destas ciências no Brasil. Exemplos dessa mirada foi oferecido pelos trabalhos de Dante Moreira Leite (2002), Renato Ortiz (2003), Tomas Skidmore (1976) e Lilia Schwarcz (1993), dentre tantos outros, que passaram a registrar em seus estudos as dimensões ideológicas, não só da obra de Silvio Romero, mas de toda a sua geração.

A pesquisa de Lilia Schwarcz (1993) constatou que o argumento racial, principalmente na FDR, foi política e historicamente construído nesse momento por nossas elites intelectuais. A sociologia havia assumido a condição de argumento fundamental nesse processo. Thomas Skdimore (1976) apontou que Silvio Romero foi um dos pioneiros da tentativa de explicar e entender os dilemas brasileiros de então a partir da ideologia do branqueamento. Renato Ortiz (2003) sugeriu que suas ideias eram implausíveis e possuíam a função de justificar as condições reais de uma república que se implantava como nova forma de organização política e econômica e, por outro, possibilitam o conhecimento nacional, projetando para o futuro a construção de um Estado brasileiro. De acordo com Dante Moreira Leite (2002), eles construíram teorias que se configuravam como justificativa ideológica do imperialismo, legitimando o domínio europeu sobre os demais povos.

Todas essas imagens cabem na obra de Silvio Romero e aos usos da sociologia naquele momento. Elas podem ser vislumbradas se levarmos em consideração a apreciação de suas contradições oferecida por Antônio Candido: 
Suas contradições se forem tomadas ao nível profundo, constituem a projeção, no seu pensamento, da complexidade perturbadora de uma sociedade marcada por certas desarmonias e discordâncias. Justamente por isso, sua obra é mais do que uma construção bem feita, que satisfaz em si mesma: ela é uma imagem nervosa do país (Candido, 1978, p. XII).

\section{Crítica literária, sociologia e os discursos sobre a identidade nacional}

0 percurso dos intelectuais da geração 1870 passava inexoravelmente pela imersão na seara da literatura. Foi a literatura a primeira fonte utilizada para pensar a invenção da sociedade brasileira e o primeiro objeto de estudo da sociologia de Silvio Romero. É a partir dessa constatação que podemos compreender Antônio Candido (1988) quando salientou que o período de formação desses intelectuais na FDR foi marcado pela manifestação contra o romantismo e pela tentativa de circunscrição das "bases modernas para o nosso pensamento e o estudo de nossa cultura" (Candido, 1988, p. 41). Foi o primeiro impulso ao trabalho do crítico Silvio Romero, na qual manifestou a preocupação com as fundações da literatura brasileira do ponto de vista naturalista. Nesta perspectiva, conceitos como os de raça, meio, evolução histórica, foram utilizados como referências para pensar a formação da sociedade brasileira. A crítica destacava-se na

[...] maneira de aplicar na literatura as grandes descobertas científicas do tempo [...] Ao mesmo tempo que procura lançar a poesia da sua pátria num trilho moderno, o jovem escritor tenta alicerçar a própria crítica literária em princípios que haviam feito dela, na Europa, um instrumento magnífico de conhecimento. 0 seu intento é transformá-la (a crítica) de comentário em norma científica. Para isto, atira-se ao debate dos elementos condicionantes da cultura com um duplo objetivo. [...] mostrar a fraqueza e a artificialidade do romantismo, indianista ou boêmio [...] traçar o caminho da renovação intelectual da sua terra (Candido, 1988, p. 42). 
O testemunho do próprio Silvio Romero [1906] (2001) é instrutivo para o esclarecimento da sua ênfase na abordagem sociológica dos fenômenos literários e culturais. Segundo ele, naquele momento (nas décadas de 1870 e 80), já havia deixado de perceber

[...] em tais criações - as obras literárias - a obra do acaso, do capricho ou das imposições de um poder estranho qualquer. Eram estas últimas presumidas manifestações da metafísica do absoluto em tal ordem de assuntos. A crítica moderna desterrou do seio esta classe de fantasmas. É que chegou definitivamente a estabelecer que a literatura é apenas um ramo das criações artísticas, a arte da palavra escrita ou falada, que como toda arte, não passa de um capítulo da sociologia, qual acontece à religião, à moral, ao direito, à política, à ciência, à indústria. Ora, o fundamento de toda a sociologia, a sua condição primordial vem a ser terra e gente, o meio e a população (Romero, 2001, p. 23).

Roberto Ventura (2001) insinuou que Silvio Romero enquanto cultor da literatura enfatizava em demasia os aspectos históricos e sociais que estavam envolvidos no processo de criação literária e cultural. "Ganhava, assim, como investigador da sociedade e da cultura o que perdia como crítico literário" (Ventura, 2001, p. 17).

Alfredo Bosi (1982, p. 280) afirmou que o enfoque utilizado por esse autor em sua crítica literária foi o passo decisivo para uma crítica sociológica de estreita observância, propondo de maneira rigorosa uma abordagem da obra em função das realidades sociais e antropológicas.

As primeiras análises sobre o fenômeno literário no Brasil dos novecentos, assentadas em presumidos critérios objetivos, contaram com a significativa contribuição da geração de 1870 . Extremamente influenciados pelos vislumbres do positivismo, buscaram uma literatura nacional com obras e autores originais, 
entendendo que estas obras e esses escritores permitiriam a afirmação da autonomia e da soberania do recente estado-nação. 0 objetivo era circunscrever e construir a identidade nacional a partir do estudo das obras literárias.

Nesse cenário, o texto era percebido como reflexo das condições sociais e naturais e adotava como critério para sua interpretação o grau de correspondência entre a literatura e a sociedade. As obras literárias e artísticas, inclusive as manifestações populares de natureza oral e folclórica, foram tidas como dados e sintomas que revelariam a psicologia de um século, de um povo, de uma nação ou, como era usual e estratégico à época, de uma raça.

Segundo Romero [1880] (2002a), a literatura romântica e a indianista eram efeitos de uma imitação e desmereciam o componente negro e mestiço no processo de inspiração de obras e fenômenos culturais que manifestavam a autenticidade da situação nacional. 0 que existia como realidade modeladora da "excentricidade" e singularidade do brasileiro não estava apenas no português, no índio ou no africano. Essa realidade, apreendida em função de fatores biossociológicos, era o mestiço.

Durante o século XIX, salientou Octavio Ianni (1992, p. 128), o debate nacional estava polarizado em termos do indianismo e europeísmo. A mesma literatura que trabalhava o mito da raiz indígena da sociedade brasileira trabalhava também uma imagem mais abrangente da sociedade como um todo. Gonçalves Dias e José de Alencar não só retratavam os índios como articulavam escravos e livres, índios, negros e brancos, portugueses e brasileiros, ou raça, população e povo. Da mesma forma, o indianismo de Bonifácio e Varnhagen também entrava na fisionomia da população brasileira. Todos estavam inventando a nação.

As noções de raça e natureza, de trópicos e miscigenação, atraso e devir, eram as pautas do século XIX no Brasil. Um povo branco 
ou mestiço? Cultura ou barbárie? Poderia haver civilização? Estes são os dilemas que se impunham aos críticos e intelectuais que buscavam entender o resultado desse processo em seus vários aspectos. Os tipos de literatura e os estilos criados no meio tropical passam, então, a ser entendidos e explicados a partir da ideia de singularidade da formação brasileira.

Alfredo Bosi (1982) fez um interessante apanhado que expressa a relação entre a literatura e a sociologia no itinerário de Silvio Romero:

As linhas de força do pensamento romeriano no que toca às letras brasileiras podem resumir-se nas seguintes premissas: a) a literatura - como as demais artes o folclore exprime diretamente os fatores naturais e sociais: o clima, o solo, as raças e seu processo de mestiçagem (determinismo bio-sociológico); b) a seqüência dos fatos na História ilustra a interação dos fatores mencionados; mas ela não é cega, tem um sentido: o progresso da Humanidade (Evolucionismo); c) a melhor crítica literária será, portanto, genética e não formalista. Os critérios de juízo darão valor ao poder, que a obra deve possuir, de espelhar o meio, e não a seus caracteres de estilo (crítica externa vs. crítica retórica).

0 enfoque de Romero foi, assim, o primeiro passo decisivo para uma crítica sociológica de estreita observância. Rejeitando as teses românticas e indianistas por subjetivas (Alencar e Magalhães) e os resíduos de uma literatura acadêmica (Sotero dos Reis), Silvio propôs vigorosamente uma abordagem da obra em função das realidades antropológicas e sociais, vistas como fatos primeiros e inarredáveis (Bosi, 1982, p. 280).

Outro momento do itinerário de Silvio Romero, demarcado por Antônio Candido (1988), que vai de 1880 a 1888, é o período cognominado de "cristalização" das ideias. São os instantes em que nosso autor aperfeiçoou os instrumentos de crítica e interpretação por intermédio de um levantamento empírico dos elementos culturais do Brasil. Voltou, então, sua atenção para o 
estudo da cultura popular e das manifestações folclóricas - "tradições, contos, cantigas, costumes e a linguagem do povo brasileiro" - culminando com a publicação dos "Cantos Populares do Brasil" [1883] (1985) e "Contos Populares do Brasil" [1885] (1985).

Câmara Cascudo (1985, p. 17) fez referência à contribuição de Silvio Romero afirmando que ele foi edificador do primeiro documentário da literatura oral brasileira. Em outra circunstância, esse mesmo autor afirmou que ele

[...] foi o maior divulgador e agitador das ideias culturais de sua época. Iniciou a história literária no Brasil. 0 folclore lhe deve as primeiras coleções de cantos, contos e poesias populares, explicações, comentários, valorizações, enfrentando a indiferença e a ignorância do ambiente (Cascudo, 1997, p. 825).

Um dos trabalhos de Silvio Romero que circunscreveu as orientações sociológicas utilizadas para o entendimento da literatura e da sociedade brasileira foi "Introdução à História da Literatura Brasileira" [1882] (2002). Neste estudo, temos uma boa oportunidade de perceber o alicerce que guiou a sua apreensão sociológica da formação brasileira. Num momento em que poucos trabalhos se aventuraram a compor um panorama da história da literatura brasileira, advertiu ele que

[...] a história do Brasil, como deve ser hoje compreendida, não é, conforme se julgava antigamente [...] a história exclusiva dos portugueses na América [...] é antes a história da formação de um tipo novo pela ação de cinco fatores, formação sextiária em que predomina a mestiçagem. Todo brasileiro é um mestiço, quando não no sangue, nas ideias. Operários deste fato inicial hão sido o português, o negro, o índio, o meio físico e a imitação estrangeira. [...] Para tanto, é antes de tudo mister mostrar as relações de nossa vida intelectual como história política, social e econômica da nação: 
será preciso deixar ver como o descobridor, o colonizador, o implantador da nova ordem de coisas, o português em suma, foi-se transformando ao contato do índio, do negro, da natureza americana, e como, ajudado por tudo isso e pelo concurso das ideias estrangeiras, se foi aparelhando o brasileiro, tal qual ele é desde já e ainda mais característico se tornará no futuro [...] Pretendemos escrever uma introdução naturalística à história da literatura brasileira. Munidos do critério popular e étnico para explicar o nosso caráter nacional, não esquecermos o critério positivo e evolucionista da nova filosofia social quando tratamos de notar as relações do Brasil com a humanidade geral (Romero, 2002, pp. 124-127).

Desse modo, Silvio Romero indicou a necessidade de circunscrição da singularidade da nação brasileira. A literatura foi a fonte capaz de fornecer esses indícios. Para Silvio Romero, o cruzamento e a mistura foram fatores determinantes da sensibilidade da produção literária brasileira. Segundo ele, a união de povos em tão variados influiu na psicologia do povo brasileiro e nas suas criações artísticas.

Consoante Silvio Romero (2001, p.59), foi possível, "à luz dos fatos e da ciência", concluir que

[...] a incorporação do índio e do negro entre nós foi conveniente para garantir o trabalho indispensável à produção da vida econômica do povo novo que ia se formar; e o mestiçamento deles com o europeu foi vantajoso em vários aspectos. Primeiro, ele foi indispensável para a formação de uma população aclimada ao novo meio. Segundo, favoreceu a civilização das duas raças menos avançadas. Terceiro, tornou possível unidade da geração futura, que jamais se daria se os três povos permanecessem isolados em face um do outro sem se cruzarem. E por último, chega ao seu intento inicial, ou seja, entende o mestiçamento como fundamental para o desenvolvimento das faculdades estéticas da imaginativa e do sentimento, fato real no próprio antigo continente, como demonstrou o ilustre de Gobineau (Romero, 2001, p. 59). 
A dimensão naturalística em Romero não soterrou a dimensão histórica e a sua importância dentro do horizonte dos fenômenos que permitiam a compreensão do Brasil e de seu malogro. Neste sentido, Silvio Romero atentou para a necessidade de entendimento e recapitulação das condições históricas concretas que determinaram a situação da sociedade brasileira. 0 seu diagnóstico para tal situação apontou que:

A avaliação da economia brasileira é a seguinte: um país com uma agricultura arruinada, (assentada em grandes propriedades, resquícios das capitanias hereditárias), relações servis estereotipadas na figura do agregado (extorsão cruel feita aos negros e proletários rurais), pequena indústria e comércio quase todo estrangeiro. 0 que resta para o grosso da população? 0 pauperismo completo, ou os empregos públicos (forma bastarda de pauperismo) (Romero, 2002, p. 159).

Durante mais de três séculos foi o Brasil governado por prepostos de um governo absoluto. Retalhado a princípio em capitanias, mal divididas e mal determinadas, que foram entregues a alguns aventureiros e áulicos, que nos fez ter também nossa idade feudal, passou depois ao domínio direto da coroa, que tratou de segregá-lo do mundo e explorá-lo. Num e noutro sistema o índio era considerado uma fera, que devia ser caçada; o negro uma máquina, que devia estupidificar-se para produzir; o peão português, o colono, um ente de sangue bastardo, distante do sangue azul, escravos dos fidalgos e de El rei, nosso senhor! ... Nestas condições, as populações que se iam formando no país, traziam a marca da origem: - a submissão (Romero, 2002, pp. 160-161).

Toda a expressiva produção de Silvio Romero durante as décadas de 1870 e 1880 foi coligida nos 05 volumes da "História da Literatura Brasileira" publicados em 1888. Livro pioneiro quanto ao registro e análise, tinha como fito selecionar elementos para pensar a nação brasileira e seu lugar no concerto das civilizações, de quase toda a produção literária no Brasil. Segundo Gilberto Freyre: 
É difícil imaginar a literatura moderna no Brasil sem Silvio Romero. Sem sua obra revolucionária de historiador e sem sua voz impaciente de profeta. 0 gigante quase sempre zangado e as vezes agressivo foi uma espécie de São Cristóvão das letras nacionais. Carregou nos rijos braços valores ainda débeis com os quais a literatura em nosso país, vem se afirmando genuinamente brasileira (Freyre, 1980, p. 05).

Uma das contribuições do trabalho de Silvio Romero foi a de ter ampliado a possibilidade de identificar o caráter nacional brasileiro a partir do que tinha sido escrito, contado e cantado no Brasil. Usou o critério nacionalista para julgar determinadas obras e manifestações culturais, buscando o caráter nacional latente nas diversas manifestações da cultura brasileira. Encontramos esse caráter, escreveu Silvio Romero [1888] (1980, p. 1502), "na índole, na intuição, na visualidade interna, na psicologia do escritor. Tomasse Tólstoi um tema brasileiro, haveria de tratá-lo como um russo" (Romero, 1980, p. 1502).

Queremos dizer com aquela maneira de sentir e pensar, aquela visão interna das coisas, aquele tique, aquele sestro especial, se assim nós podemos expressar, que são os modos de representação espiritual da inteligência brasileira [...] Machado de Assis não sai fora a lei comum, não pode sair e aí dele se sair. Não teria valor. Ele é um dos nossos, um genuíno representante da sub-raça brasileira cruzada [...] seus romances, seus contos, suas comédias encerram vários tipos brasileiros, genuinamente brasileiros (Romero, 1980, p. 1502).

Nas páginas da "História da literatura brasileira" está sintetizada a importância da miscigenação, atribuída por esse autor, na formação da sociedade brasileira. Segundo Silvio Romero "um dos fenômenos mais interessantes no estudo das criações populares é o que se pode chamar de mestiçamento [...] de nossa literatura anônima, indicando as várias origens de nossos cantos e contos" (Romero, 1980, p. 153). Esse dado pode ser percebido 
e encontrado nos mais variados aspectos da nossa cultura, nas "cantigas populares, romances, orações, parlendas [...] não se denuncia somente na linguagem; manifesta-se nas fontes mais íntimas das inspirações" (Romero, 1980, p. 161).

\section{Lugares da miscigenação e de Sílvio Romero no campo da} sociologia brasileira

As instruções de Randall Collins (2001), em estudo dedicado ao entendimento das comunidades intelectuais, indicam que todo universo intelectual prescinde de atos intelectuais - conferências, debates, discussões - que se desenvolvam fazendo menção aos textos passados, ora organizando e elaborando questões e pesquisas a partir deles, ora censurando-os e negando certas possibilidades de conhecer. Os intelectuais são reservadamente conscientes de seus predecessores. Os seus produtos vão direcionados a um público específico. Quando a fala e a pregação são feitas em rede, em função de um conjunto de alunos, de colegas ou discípulos, aquela mensagem vai se tornando subliminarmente um elemento de uma cadeia, que será repisada, debatida e aumentada a depender das circunstâncias materiais que sustentem estas redes.

Silvio Romero é uma dessas referências que estão situadas no passado e que contribuíram para a demarcação de uma forma de interpretar o Brasil. Geralmente um relevante trabalho, avaliado pelo critério histórico, é identificado quando é amplamente reconhecido em determinado campo cultural e amplia os limites da fala de seus pares. Essa ampliação se dá em função dos acertos, das incorreções, das limitações que certas perspectivas possuem e que acabam se tornando a origem da inclinação e do fascínio que elas exercem.

No seu afã de interpretar sociologicamente o Brasil, Silvio Romero encontrou uma chave para interpretar a identidade nacio- 
nal brasileira que emerge do pressuposto sociológico de que a contribuição do negro e da miscigenação são duas importantes forças motrizes da cultura brasileira. Neste sentido, Silvio Romero [1906] (2001, p.51) foi um dos primeiros a notar, registrar e inserir o negro como elemento fundamental para o entendimento da formação da sociedade brasileira. Alertou que:

[...] dos negros é que ninguém se quis jamais ocupar, cometendo-se, assim, a mais censurável ingratidão de toda a nossa história [...] É indispensável restituir aos negros, o que lhe tiramos: o lugar que lhe compete em tudo que tem sido praticado no Brasil. E o que mais admira é que o não tenham já feito tantos negros e mestiços ilustrados, existente no país (Romero, 2001, p. 51).

Salta aos olhos, registrou Romero, num breve relance sobre os dados demográficos do Brasil, o fato do contingente de negros representarem, por si e por seus parentes mestiços, dois terços da população.

Na ordem econômica, foram eles principalmente que abriram caminhos, desbravaram as terras, cultivaram os engenhos e fazendas, mineraram os terrenos auríferos e diamantinos e fizeram todo o serviço doméstico; foram assim os principais fatores da riqueza pública e particular [...] $\mathrm{Na}$ história política, civil, literária, artística, sua colaboração foi de todos os tempos, por intermédio principalmente de seus parentes mestiços, com seus jornalistas, seus oradores, seus jurisconsultos, seus poetas, seus artistas [...] No contato perene de nossas famílias influíram o negro profundamente no caráter nacional por meio de seus hábitos, de suas usanças, de suas predileções, de suas lendas, de seus cantos, de suas tendências psicológicas [...] podemos à luz dos fatos e da ciência, concluir: o incorporamento direto do índio e do negro entre nós foi conveniente para garantir o trabalho indispensável à produção da vida econômica do povo novo ia se formar; e o mestiçamento deles com o europeu foi vantajoso: a) para a formação de uma população aclimada ao 
novo meio b) para favorecer a civilização das duas raças menos avançadas c) para preparar a possível unidade da geração futura, que jamais se daria se os três povos permanecessem isolados em face um do outro sem se cruzarem d) para desenvolver as faculdades estéticas da imaginativa e do sentimento, fato real no próprio antigo continente, como demonstrou o ilustre de Gobineau (Romero, 2001, p.57-59).

Uma reflexão que captou um dos termos que demarcam o universo e os dilemas em que a sociologia era recepcionada no contexto escravocrata brasileiro dos novecentos foi percebida por Oracy Nogueira (1978). Para ele, o interesse que orientou a recepção dessa ciência no Brasil foi a perplexidade de uma elite letrada, preocupada com a identidade e o destino da sociedade nacional. Essa perplexidade era atenuada pela ambivalência dos intelectuais brasileiros no século XIX "em relação ao contexto que estavam inseridos: vendo-os com os olhos do europeu, exacerbavam seus aspectos negativos, sem conseguir romper com os laços afetivos que a ele os prendiam" (Nogueira, 1978, p. 185).

As informações de Lilia Schwarcz (1993) corroboram o efeito da imersão desse autor nesse dilema. Silvio Romero

[...] encontrava na mestiçagem o resultado da luta pela sobrevivência das espécies, como estabeleciam as teorias deterministas da época. Porém, paradoxalmente, ao invés de condenar a hibridação racial, seguindo os modelos evolucionistas sociais, esse autor encontrava nela a futura viabilidade nacional (Schwarcz, 1993, p. 154).

Conforme Thomas Skidmore (1976),

[...] os escritos dessa época de Romero refletem bem a inconsistência que a justaposição dos costumes domésticos e da teoria importada tinha como efeito inevitável. No fim do império ele fora dos primeiros a pedir que se reconhecesse o Brasil como produto da miscigenação (Skidmore, 1976, p. 72). 
Antônio Candido (1978, p. XII) caracterizou o trabalho de Silvio Romero como marcado por um derrotismo pessimista e ao mesmo tempo um forte patriotismo. Para Evaristo de Moraes Filho (1985), Silvio Romero e Tobias Barreto foram cientificistas à outrance e almejaram sempre cautela

[...] pregando a ordem, a disciplina, a hierarquização das forças sociais, com repúdio quase constante da agitação, da insurreição ou da revolução, formas reprováveis de anarquia. 0 mecanicismo dos seus primeiros inspiradores, alguns ensinamentos de Comte e o individualismo de Spencer cortavam-lhes as asas e não permitiam maiores ousadias além do seu horizonte e do seu tempo. Foram rebeldes ambos, mas nunca chegaram a revoltados ou revolucionários, como eles próprios confessariam mais de uma vez. Se nunca adotaram uma filosofia social maquiavélica, por outro lado jamais chegaram ao pensamento utópico [...] a utopia e o sonho sempre os assustaram, porque lhes pareciam o falseamento da verdade, o afastamento das sólidas bases da ciência fundada na observação e na experimentação [...] o cientificismo matou a utopia [...] não lhe faltaram sensibilidade nem coragem para denunciar o pauperismo, a miséria, o desamparo do povo, as desigualdades sociais, mas ou acharam que não tinham remédio, ou desistiram de encontrá-lo [...] rebeldes, sim; mas revolucionários, nunca (Moraes Filho, 1985, pp. 68-69).

Não obstante essa atitude apreensiva no tocante à miscigenação, decorrente da ambiguidade posta pela artimanha colonial, é manifestada por toda a sua obra uma tensão entre pessimismo e otimismo acerca do futuro brasileiro. "Manda a verdade afirmar ser o mestiçamento uma das causas de certa instabilidade moral na população, pela desarmonia das índoles e das aspirações no povo, que traz a dificuldade da formação de um ideal nacional comum" (Romero, 2001, p. 59). Em outra circunstância afirmou que o

[...] Brasil é um país democrático. Filho da cultura moderna, nascido na época das grandes navegações e das grandes descobertas, o que importa dizer, depois da constituição 
forte da plebe e da burguesia, ele é, além do mais, o resultado do cruzamento de raças diversas, onde evidentemente predomina o sangue tropical. Ora, os dois maiores fatores da igualdade entre os homens são a democracia e o mestiçamento. E estas condições não nos faltam em grau algum, temo-las de sobra (Romero, 1894, p. 15).

Conforme Silvio Romero, a sua intenção com o livro "Introdução à História da Literatura Brasileira" [1882] foi a de que ele se tornasse "um protesto, um grito de alarma de são brasileirismo, um brado de entusiasmo para um futuro melhor" (Romero, 2002a, p. 162). Em outra situação, afirmou que "os defeitos apontados, porém, são defeitos que podem ser reduzidos por uma severa educação" (Romero, 2001, p. 59).

\section{No seu trabalho "A Literatura Brasileira e Crítica Moderna" [1880], ele manifestou uma representação significativa do valor atribuído à miscigenação como categoria analítica da sociedade brasileira.}

A literatura brasileira, como todas as literaturas do mundo, deve ser expressão positiva do estado emocional, dos sentimentos de um povo. Ora, nosso povo não é o índio, não é o negro, não é o português; é antes a soma de todas estas parcelas atiradas no caminho do novo mundo. São as gerações crioulas, que, deixadas de parte das nostalgias dos progenitores, esqueceram-se delas para amar este país e trabalhar na formação da nova pátria [...] o advento do elemento novo, do genuíno brasileiro - mestiço, o filho do país.

Quando falo do mestiço não quero me referir somente ao mestiço fisiológico, o mulato; refiro-me a todos os filhos da colônia, todos os crioulos, que o eram no sentido lato; porquanto, ainda que nascessem das raças puras, o eram no sentido moral. Eu me explico [...] 0 proprietário é um português rico; tem seus prejuízos de raça, que ter uma descendência limpa, e por isso contraiu matrimônio com a filha de um mercante abastado da praça, português como ele.

Vai-lhe saindo a prole alourada, mostrando através da cútis macia os fios distintos do sangue azul. Mas o nosso homem 
rico, e sê-lo no Brasil, máxime naqueles bons tempos, era possuir algumas dúzias de escravos, e eles os tinham, não só da terra como de Guiné. Como era natural, estes últimos também procriavam! Ora, o meio tem suas exigências atrozes; o resultado vinha a ser que os filhos do senhor de engenho eram limpos de tez; mas, gostando muito de ir às senzalas a conversar e brincar com os moleques, as pretas e as caboclas velhas, saiam no fim de contas uns portuguesitos, é verdade, mais uns tais, que distavam dos pais, como a água do vinho, pela intuição e pela face moral. Sabiam as lendas das caiporas, saci Pererê, da Iara, do Zumbi, do Manjelau e uma multidão de outras coisas, que sorrateiramente, e sem o quererem, as pretas e índias iam inoculando nos tenros espíritos.

Por outro lado, os filhos dos escravos, os filhos dos pretos e dos índios, perdiam também o uso de sua língua nativa e falavam a língua da casa grande, a língua do senhor; eram cristianizados e aprendiam umas tantas coisas, que só os brancos sabiam. Eis ai o que eu chamo um caso de mestiçagem moral (Romero, 2002, pp. 220-221).

Silvio Romero buscou identificar na formação social brasileira a contribuição do elemento mestiço, destacando seus principais nomes e como representavam os elementos positivos da miscigenação. A sua atitude em relação a Antônio Pereira Rebouças, Tobias Barreto, Machado de Assis, Tito Lívio de Castro, dentre tantos outros escritores mestiços, expressou seu otimismo quanto ao futuro de um país miscigenado. 0 mestiço Tobias Barreto, que ele construiu e tentou consagrar na "História da Literatura Brasileira" [1888] (1980) e em "A filosofia no Brasil" (1878) como maior intelectual brasileiro, representou a utilização antagonista das coordenadas fornecidas pelas teorias coloniais.

Silvio Romero deparou-se com um estilo de sociologia cujos conceitos fundamentais pressupunham uma atitude pessimista em relação à configuração da sociedade brasileira. Era um momento, informou Thales de Azevedo (1962), marcado por interpretações sociológicas carregadas de certo determinismo biológico e psicológico, que passam a voltar seus interesses pelo mestiço como forma de 
[...] fornecer elementos para a explicação das fraquezas e defeitos de uma sociedade otimista mais um tanto descrente das qualidades de seu povo, em sua maioria ainda jungido ao primitivismo das mentalidades bárbaras que o positivismo colocava no degrau mais baixo e antigo no degrau das civilizações (Azevedo, 1962, p. 74).

No entendimento de Alfredo Bosi (1982):

Hoje os cânones evolucionistas já estão em crise ou, pelo menos, relativizados; as reservas para-racistas que Silvio tinha em comum com os antropólogos do tempo já não nos fazem mal; enfim, não cessam de refinar os métodos de análise da obra literária: temos, portanto, armas para reler criticamente os escritos do mestre sergipano e deles extrair o muito que ainda podem oferecer em documentação e, o que mais importa, em interesse constante sob todas as faces de nossa realidade. É a partir de Silvio que se deve datar a paixão inteligente pelo homem brasileiro, pedra de toque de uma linhagem de pesquisadores e críticos que se estenderia até os nossos dias contando, entre outros, com os nomes de Euclides da Cunha, João Ribeiro, Nina Rodrigues, Oliveira Viana e, a partir do Modernismo, Mário de Andrade, Roquette Pinto, Gilberto Freyre, Artur Ramos, Josué de Castro, Câmara Cascudo, Caio Prado Jr., Nelson Werneck Sodré, Cavalcanti Proença, Cruz Costa, Sérgio Buarque de Holanda, Florestan Femandes e Antonio Cândido (Bosi, 1982, p. 281).

Apresentadas essas considerações, chegamos ao momento de tentar circunscrever alguns aspectos da contribuição de Silvio Romero ao pensamento sociológico brasileiro. Afinal, é plausível sugerir que houve uma apropriação dos resultados e interpretações de Silvio Romero pelo campo da sociologia brasileira?

0 resultado do estudo de Alberto Schneider (2005, p. 243) sobre a obra de Silvio Romero sugere que existem "resquícios sutis e vigorosos da velha leitura romeriana do Brasil nas páginas freyreanas. Cotejar as obras desses autores revela pontos de contato mais profundos do que habitualmente se supõe". 
A percepção de que a miscigenação étnica e cultural entre as três raças teria formado a nacionalidade brasileira foi uma invenção oitocentista - que teve em Silvio Romero um de seus maiores artífices - legado que mais tarde Gilberto Freyre atualizou e sofisticou, dotando-o de inédita força e prestígio (Schneider, 2005, p. 244).

Para Antônio Candido, Silvio Romero influiu "diretamente no modo de Gilberto Freyre conceber a gênese das classes dominantes" (Candido, 1878, p. XIII). Pinto Ferreira sugestionou que a influência de Romero estaria "numa linha ideológica que mais tarde seria trilhada e aproveitada por Gilberto Freyre, em sua sociologia, pois na verdade a concepção sociológica do aludido autor representa apenas uma recontinuação em uma nova fase de desenvolvimento, das ideias do mestre sergipano" (Ferreira, 1981, p. 106). Ricardo Souza (2007, p.63) também indicou essa relação de continuidade com Gilberto Freyre ao registrar que Silvio Romero já havia, como este, notado a tendência e propensão do "português miscigenado" em constituir uma "nova raça mestiça".

Em recente trabalho (Barbosa, 2010), desenvolvemos essa intuição apontando que Gilberto Freyre era leitor de Silvio Romero e incorporou timidamente sua obra, como bem observou Alberto Schneider (2005), explorando-o enquanto fonte sobre cultura brasileira e desenvolvendo as sendas abertas pelas suas sugestões. A percepção de que a história da formação do Brasil deveria levar em conta a natureza da miscigenação era autenticamente sociológica e esteve presente em seus três significativos trabalhos sobre a história da sociedade patriarcal no Brasil. Defendemos a hipótese, naquele momento, que a rejeição teórica dos aspectos raciais e o valor atribuído por Silvio Romero a eles como variável para interpretar a sociedade brasileira fizeram com que Gilberto Freyre não assumisse abertamente essa filiação e não a repercutisse em sua obra.

Em “Casa Grande e Senzala” [1933] (2000) ele recuperou de Silvio Romero a ideia de contribuição do negro e do indígena na 
formação dos costumes e da cultura brasileira, além de utilizar o autor como fonte sobre os costumes e as relações sociais na colônia.

Em “Sobrados e Mocambos" [1936] (2000a), a referência se deu em torno da questão da importância da miscigenação como fator dinâmico da sociedade brasileira, indicando em certos momentos como Silvio Romero percebia a importância do mestiço, particularmente o aristocratizado pelo título de bacharel e escritor, ao ocupar posições de destaque nas funções públicas. "O mestiço, o mulato, digamos delicadamente, o moreno, na acepção já assinalada por Silvio Romero, parece vir revelando maior inteligência de líder que o branco ou quase branco" (Freyre, 2000a, p. 1295). Neste caso, Gilberto Freyre apontou para o fato de que ele já havia notado que o declínio do patriarcado rural era manifestado pela

[...] transferência de poder, ou de soma considerável de poder, da aristocracia rural, quase sempre branca, não só para o burguês intelectual - o bacharel ou doutor às vezes mulato - como para o militar - o bacharel da escola militar e da escola politécnica, em vários casos negróides (Freyre, 2000a, p. 1226).

Em “Ordem e Progresso" [1959] (2000b, p. 751) há referências ilustrativas da relação entre Gilberto Freyre e Silvio Romero. Ele apontou certo pessimismo característico daquela geração em relação ao Brasil, mas segue a trilha de Silvio Romero ao perceber como os traços nacionais já se manifestavam na música, na culinária, na literatura e na cultura de uma maneira geral, caracterizando a obra deste autor como autêntica representante de um "brasileirismo cultural".

Para Gilberto Freyre (2000b, p. 483) a relação de Romero com a questão da "interpenetração das raças" foi muito contraditória. Ora ele defendia, ora não. 
Quanto a Romero - por vezes campeão ardoroso do melanismo - faltou-lhe neste ponto coerência. Mesmo assim, suas atitudes foram antes no sentido de favorecer que no de impugnar o que fosse tendência brasileira à melanização do homem ou da gente nacional (Freyre, 2000b, p. 472).

Gilberto Freyre ressoou, a partir de novos horizontes, a abordagem iniciada pelo nosso intelectual novecentista. No centenário de nascimento de Silvio Romero, Gilberto Freyre comentou a importância da "História da Literatura Brasileira", assinalando que ela é como

[...] um desses livros que protegem um povo contra a agressão e o desânimo, como se fossem fortalezas, e, ao mesmo tempo, igrejas. Que se levantam contra os que descrêem dos valores nacionais de cultura e contra os que agridem esses valores por considerá-los perniciosos ou maus. Na verdade o que Silvio Romero nos deixou neste livro monumental foi a afirmação do devido poder de desenvolver uma literatura diferente da portuguesa. Uma literatura-reflexo da nossa cultura mestiça e expressão da nossa condição de americanos (Freyre Apud Schneider, 2005, p. 243).

Os temas dominantes em cada campo do conhecimento são os que definem o que num certo momento deve ser estudado e delimitam as questões importantes para os pesquisadores, sobre as quais eles devem concentrar seus esforços. Entretanto, as redes e o universo intelectual operam também a partir das lacunas e limites deixados por certas interpretações. Gilberto Freyre mudou as coordenadas que operavam o entendimento da cultura brasileira no século XIX, no entanto, manteve a intuição fornecida pelos trabalhos de Silvio Romero. Ao invés de levar em consideração os "vícios hereditários", a "inferioridade psíquica", o "atraso evolutivo" que resultavam (supostamente) da miscigenação, Gilberto Freyre operou, conforme Thales de Azevedo (1962, p. 76), "uma autêntica revolução no método da história social e da Antropologia cultural nacionais". Ele deixou de examinar a mestiçagem para 
[...] além dos termos gerais do problema, isto é, reduzindo às proporções reais as correlações entre o substrato orgânico e o biótico e as forças históricas que atuaram na vida brasileira desde a inauguração desta como cultura autônoma no tempo da Colônia, e tratando com fatores distintos em sua gênese a raça e a cultura [...] em Gilberto Freyre a miscigenação [...] é apreciada como um fenômeno de outra ordem, diríamos mais nobre, de natureza social e de sentido positivo, um corretor das distâncias sociais e do profundo hiato cultural entre o branco e o indígena, particularmente entre aquele e o negro, entre o senhor e o escravo ou liberto, entre o civilizado e o bárbaro, entre a casa grande e a senzala (Azevedo, 1962, pp. 76-77).

A "reinterpretação do mestiço" e da "mestiçagem", consoante Thales de Azevedo (1962), permitiu que Gilberto Freyre ocupasse uma "posição que nenhum outro intérprete da nossa civilização já assumira; e leva-o a sugerir a hipótese de que, além de promover a mobilidade horizontal e vertical das pessoas de cor, ela atuou como forte elemento de integração transnacional ou supra nacional das populações assim formadas" (Azevedo, 1962, p. 78).

Embora essas intuições sejam objetos de críticas e alvo de controvérsias por serem acusadas de dissimular e dificultar a delimitação dos horizontes das práticas racistas historicamente construídas na sociedade brasileira, elas não devem turvar o horizonte deste trabalho que intentou mostrar como Silvio Romero fora localizado na história da sociologia no Brasil, como esta ciência foi recepcionada a partir da crítica literária e indicar como as intuições de Silvio Romero puderam ser incorporadas por Gilberto Freyre, e quiçá pela sociologia brasileira, para orientar os debates sobre os usos da compreensão de aspectos relevantes e controversos da formação da sociedade brasileira.

Como já havíamos observado em estudo sobre a Escola de Recife e a Sociologia no Brasil, se existe uma linhagem de sociologia propugnada por essa escola inventada por Silvio Romero, ela só pode ser 
medida a partir da controversa percepção sobre a ideia do papel do mestiço e da mestiçagem na construção e formação da cultura brasileira. É isso que permite a associação entre Gilberto Freyre a essa escola. Sua relação com a sociologia não foi autodidata e sob os auspícios do curso de direito, e de sua dimensão beletrista, como havia sido a da geração antecessora. Ele foi adestrado para entender de forma sociológica a formação da sociedade brasileira e desenvolveu a vereda deixada por Romero. Contextualizada, o principal erro da obra de Romero estava nas relações que mantinha com teóricos do racismo e do evolucionismo. Em termos de história da sociologia no Brasil, talvez um dos feitos de Gilberto Freyre foi o de ter atravessado essa perspectiva teórica e desdobrado de forma sociológica e antropológica o tema da mestiçagem.

\section{Ref erências Bibliográficas:}

Azevedo, Thales. Gilberto Freyre e a reinterpretação do mestiço. In: Gilberto Freyre: sua ciência, sua filosofia, sua arte. Rio de Janeiro, José Olympio editora, 1962.

Barbosa, Ivan. A Escola de Recife e a sociologia no Brasil. 2010, 338p. Tese (Doutorado em Sociologia) PPGS, Universidade Federal de Pernambuco, Recife.

Bomfim, Manoel. [1905] América Latina: Males de Origem. Rio de Janeiro; Topbooks, (1993).

Bosi, Alfredo. História Concisa da Literatura Brasileira. 3a. Edição. São Paulo, Cultrix, 1982.

Candido, Antônio. 0 método crítico em Silvio Romero. São Paulo; EDUSP, 1988.

A Sociologia no Brasil. In: Enciclopédia Delta Larousse, Rio de Janeiro; Delta S.A, 1969.

Introdução. In: ROMERO, Silvio. Teoria, crítica e história Literária. Rio de Janeiro; LTC, São Paulo; EDUSP, 1978.

Cascudo, Luís Câmara. Dicionário do Folclore Brasileiro. São Paulo, Ediouro, 1997. 
Prefácio. In: ROMERO, Silvio. Folclore brasileiro: cantos populares do Brasil. São Paulo, Editora da Universidade de São Paulo, 1985.

Chacon, Vamireh. A sociologia e o germanismo segundo Tobias Barreto e Silvio Romero. In: Revista Doxa, Recife, Ano 5, No.08, 1959. 1977.

História das Ideias Sociológicas no Brasil. São Paulo; Edusp/Grijalbo,

. Formação das Ciências Sociais no Brasil (Da Escola do Recife ao código civil). Brasília: Paralelo 15; Brasília: LGE Editora; São Paulo: Fundação Editora da Unesp, 2008.

Collins, Randall. Sociologia de las filosofias: uma teoria global del cambio intelectual. Barcelona, Editorial Hacer, 2005.

Ferreira, Pinto. A sociologia no Brasil. In: Sociologia. Pernambuco, Companhia Editora de Pernambuco, 1969.

Freyre, Gilberto. Casa Grande e Senzala: formação da família brasileira sob o regime da economia patriarcal. Interpretes do Brasil. São Paulo/Rio de Janeiro. Record. Vol. 2, 2000.

. Sobrados e Mocambos: decadência do patriarcado rural e desenvolvimento do urbano. Interpretes do Brasil. São Paulo/Rio de Janeiro. Record. Vol. 2, 2000a.

Ordem e Progresso: introdução à história da sociedade patriarcal no Brasil. Interpretes do Brasil. São Paulo/Rio de Janeiro. Record. Vol. 3, 2000b.

. Apresentação. ROMERO, Silvio História da Literatura brasileira. Rio de Janeiro, José Olympio. 7a. Edição, 1980.

Ianni, Octavio. A ideia de Brasil Moderno. São Paulo, Brasiliense, 1992.

Leão, A. Carneiro. Panorama Sociologique du Brésil. Paris, Presses Univertitaires de France, 1953.

Leite, Dante Moreira. 0 caráter nacional brasileiro: história de uma ideologia. São Paulo, Editora UNESP, 2002.

Machado Neto, A. L. Estrutura Social da república das Letras: sociologia da vida intelectual brasileira - 1870-1930. São Paulo; Editora da Universidade de São Paulo, Editorial Grijalbo, 1973.

Mendonça, Carlos Sussekind de. Silvio Romero: sua formação intelectual (1851-1880). Rio de Janeiro, Companhia Editora Nacional, 1938.

Moraes filho, Evaristo. Medo à utopia: o pensamento social de Tobias Barreto e Silvio Romero. Rio de Janeiro, Nova Fronteira, 1985. 
Munanga, Kabengele. Rediscutindo a mestiçagem no Brasil. Belo Horizonte, Autêntica, 2004.

Nogueira, Oracy. A sociologia no Brasil. In: FERRI, G. M. \& MOTOYAMA, S. (org.). História das Ciências no Brasil. vol. 3, São Paulo, EDUSP/EPU-CNPq, 1978.

Ortiz, Renato Cultura Brasileira e Identidade Nacional. São Paulo; Brasiliense, 2003.

Rabello, Sylvio. Itinerário de Silvio Romero. Rio de Janeiro; Civilização Brasileira, 1967.

Ramos, Alberto Guerreiro. Introdução crítica à sociologia brasileira. Rio de Janeiro; Editora da UFRJ, 1995.

Romero, Silvio. [1880] A Literatura Brasileira e a Crítica Moderna. In: Literatura, história e crítica. Rio de Janeiro, Imago. Aracaju, UFS, 2002.

. [1882] Introdução à história da literatura brasileira. In: Literatura, história e crítica. Rio de Janeiro, Imago. Aracaju, Editora da Universidade Federal de Sergipe, 2002a.

[1906] Compêndio de história da literatura brasileira. Rio de Janeiro, Imago. Aracaju, Editora da Universidade Federal de Sergipe, 2001.

. [1888] História da Literatura brasileira. Rio de Janeiro, José Olympio. 7ạ. Edição, 1980.

. Negro: objeto de ciência. In: CARNEIRO, Edson. Antologia do Negro Brasileiro. Rio de Janeiro, Agir, 2005.

Schneider, Alberto Luiz. Silvio Romero, hermeneuta do Brasil. São Paulo, Annablume, 2005.

Schwarcz, Lilia Moritz. 0 espetáculo das Raças: cientistas, instituições e questão racial no Brasil - 1870 - 1930. São Paulo; Companhia das Letras, 1993.

Skidmore, Thomas E. 0 preto no branco: raça e nacionalidade no pensamento brasileiro. Rio de Janeiro, Paz e Terra, 1976.

Sodré, Nelson Werneck. Silvio Romero: um guerrilheiro desarmado. In: Ideologia do Colonialismo. Rio de Janeiro, ISEB, 1961.

Souto Maior, Heraldo Pessoa. Para uma história da Sociologia em Pernambuco: uma tentativa de periodização. In: Estudos de Sociologia. V.9, N. 1, Jan/ jun. Recife; UFPE/Líber Gráfica, 2003.

Souza, Ricardo Luiz. Identidade nacional e modernidade brasileira: o diálogo entre Silvio Romero, Euclides da Cunha, Câmara Cascudo e Gilberto Freyre. Belo Horizonte: Autêntica, 2007. 
Ventura, Roberto. Estilo Tropical: história cultural e polêmicas literárias, 1870-1914. São Paulo, Companhia das Letras, 1991.

História e Crítica em Silvio Romero In: ROMERO, Silvio. Compêndio de História da Literatura Brasileira. Rio de Janeiro; Imago. Aracaju; UFS, 2001.

Recebido em 26/01/2018

Aprovado em 10/02/2018. 